\title{
Examination of Oxygen Atom Transfer Reactivity of Heteroscorpionate Dioxo-Mo(VI) Complexes: Geometric Isomers, Solvent Effect, Intermediates, and Catalytic Oxidation
}

\author{
Ba L. Tran, Amy Arita, Andrew L. Cooksy and Carl J. Carrano* \\ Department of Chemistry and Biochemistry \\ San Diego State University \\ San Diego, CA 92182-1030 USA
}

* Department of Chemistry and Biochemistry, San Diego State University San Diego, CA, 82182-1030, USA. Fax: 619-594-4634; Tel: 619-594-1617; E-mail: ccarrano@mail.sdsu.edu

${ }^{\dagger}$ Electronic Supplementary Information (ESI) available

(C) 2015. This manuscript version is made available under the Elsevier user license

http://www.elsevier.com/open-access/userlicense/1.0/ 


\begin{abstract}
Heteroscorpionate-based $\left[(\mathrm{L} 10 \mathrm{O}) \mathrm{MoO}_{2} \mathrm{Cl}\right]$ and $\left[(\mathrm{L} 3 \mathrm{~S}) \mathrm{MoO}_{2} \mathrm{Cl}\right]$ complexes containing an interchangeable third heteroatom donor have been utilized for the systematic investigation of oxygen atom transfer (OAT) reactivity. The detection of phosphoryl intermediates and products in the reaction pathway were probed by UV-Vis, mass spectrometry, and ${ }^{31} \mathrm{P}$ NMR spectroscopy. The OAT reactivity of the metal complexes toward $\mathrm{PPh}_{3}$ were monitored by UV-Vis spectroscopy under pseudo-first order conditions. The sterically encumbered (L10O) ligand gives rise to isolable trans and cis isomers of [( $\left.\mathrm{L} 10 \mathrm{O}) \mathrm{MoO}_{2} \mathrm{Cl}\right]$ allowing investigation into the role of geometry on OAT reactivity. The OAT reactivity of the cis isomer of $(\mathrm{L} 10 \mathrm{O}) \mathrm{MoO}_{2} \mathrm{Cl}$ demonstrated a dramatic solvent dependence, in which the reaction proceeded at a measureable rate only in pyridine. However, the trans counterpart reacted in all solvents and at much faster rates. The catalytic oxidation of $\mathrm{PPh}_{3}$ to $\mathrm{OPPh}_{3}$ by trans-[(L10O) $\left.\mathrm{MoO}_{2} \mathrm{Cl}\right]$ and cis- $\left[(\mathrm{L} 3 \mathrm{~S}) \mathrm{MoO}_{2} \mathrm{Cl}\right]$ complexes using DMSO as an oxygen donor was monitored by ${ }^{31} \mathrm{P}$ NMR in DMF at $30^{\circ} \mathrm{C}$ with rates, $k_{\text {cat }}=4.26 \times 10^{-5} \mathrm{~s}^{-1}$ and $5.28 \times 10^{-5}$ $\mathrm{s}^{-1}$, respectively.
\end{abstract}




\section{Introduction}

Oxygen atom transfer (OAT) is an important class of chemical transformation in biology and chemistry. ${ }^{1-3}$ Mononuclear molybdenum enzymes are ubiquitously involved in this two electron process by shuttling a terminal oxo from the metal center to an acceptor and vice versa with the molybdenum center interchanging between the +6 and +4 oxidation states. ${ }^{4}$ These enzymes have been classified into three major families: Sulfite Oxidase (SO), Xanthine Oxidase (XO), and DMSO Reductase (DMSOR), in which all the active sites contain conserved pterindithiolene ligation to the molybdenum. ${ }^{5}$ The proper regulation and function of these enzymes affect the environment, biological metabolism, and homeostasis. For instance, mutation on the structural gene of SO causes complications from dysfunctional lipid metabolism to fatal neurological abnormalities. ${ }^{5}$

The utility of facially tridentate scorpionate and heteroscorpionate model systems has provided important spectroscopic and OAT mechanistic insights into the function and mechanism of mononuclear molybdoenzymes despite their incorporating pyrazolate donors rather than the sulfur rich environment native to the enzymes. ${ }^{6-18}$ Mechanistically a variety of computational studies have proposed that the oxygen atom transfer performed by these molybdoenzymes follows an inner sphere electron transfer mechanism proceeding through the associative formation of a bridging intermediate that subsequently decomposes to products via a dissociative pathway. ${ }^{19}$ Utilizing the Tp* system, Basu and co-workers provided direct evidence of this predicted intermediate with the crystal structure of the phosphoryl adduct complex $\left[\mathrm{Tp}^{*} \mathrm{MoOCl}\left(\mathrm{OPMe}_{3}\right){ }^{20-24} \mathrm{We}\right.$ have observed similar species via ESI-MS and UV-Vis spectroscopy utilizing the sulfur rich $\left[\mathrm{TmMeMoO}_{2} \mathrm{Cl}\right]$ complex. $^{25}$

Prompted by Basu's work and our own results, we have expanded on this research by investigating our family of heteroscorpionate complexes of the type $\left[\mathrm{LMoO}_{2} \mathrm{Cl}\right]$, where $\mathrm{L}=$ (L10O) and (L3S) shown in scheme 1. Over the last several years, we have demonstrated that these dioxo-Mo(VI) complexes significantly influenced OAT reactivity based on contribution of the third heteroatom, i.e. alkoxide, phenol, carboxylate, or thiolate. ${ }^{13}$ In addition, the introduction of steric bulk into the phenolate ligand has allowed for the isolation of both cis and trans geometric isomers and we have studied the isomerization rates from kinetically labile isomer to the thermodynamically favored product for both $\mathrm{Mo}(\mathrm{V})$ and $\mathrm{Mo}(\mathrm{VI})$. The effect of geometry on OAT reactivity of the dioxo-Mo(VI) complexes has also been superficially studied. ${ }^{12,14,16,18}$ Finally, we demonstrated a metal ion dependence between Mo(VI) and W(VI) on both isomerization kinetics and OAT reactivity. ${ }^{15,26}$ Herein, utilizing complexes of $\left[(\mathrm{L} 10 \mathrm{O}) \mathrm{MoO}_{2} \mathrm{Cl}\right]$ and $\left[(\mathrm{L} 3 \mathrm{~S}) \mathrm{MoO}_{2} \mathrm{Cl}\right]$, we explore the effect of solvent on OAT reactivity along with the detection of $\left[(\mathrm{L} 10 \mathrm{O}) \mathrm{MoOCl}\left(\mathrm{OPPh}_{3}\right)\right]$ and $\left[(\mathrm{L} 3 \mathrm{~S}) \mathrm{MoOCl}\left(\mathrm{OPPh}_{3}\right)\right]$ intermediates by mass spectrometry and ${ }^{31} \mathrm{P}$ NMR spectroscopy. Moreover, utilizing ${ }^{31} \mathrm{P}$ NMR spectroscopy, we have monitored the ability of these complexes to mediate catalytic OAT between DMSO and triphenylphosphine.

\section{Results}

trans-[(L10O) $\left.\mathrm{MoO}_{2} \mathbf{C l}\right]$. Isolation of the pure trans isomer of $\left[(\mathrm{L} 10 \mathrm{O}) \mathrm{MoO}_{2} \mathrm{Cl}\right]$ remains difficult due to its rapid conversion to the thermodynamically more stable cis isomer under a variety of conditions. The mechanism of isomerization at the metal center is proposed to occur via a trigonal twist mechanism as the bromide-chloride exchange was not observed by mass 
spectrometry. ${ }^{16}$ Optimal synthetic efforts have yielded a product with an 11:1 trans/cis ratio based on proton NMR. ${ }^{15}$

Examination of the OAT reactivity of trans-[(L10O) $\left.\mathrm{MoO}_{2} \mathrm{Cl}\right]$ in acetonitrile, DMF, benzene, and pyridine under pseudo-first order conditions with 50-fold excess of phosphine was monitored by UV-vis spectroscopy. On mixing of acetonitrile solution of trans[(L10O) $\left.\mathrm{MoO}_{2} \mathrm{Cl}\right]$ and phosphine, the optical spectra depicted in figure 1 (top) showed a rapid increase of the band at $400 \mathrm{~nm}$ and simultaneous appearance of the weak, broad, d-d transition band in the 600-800 $\mathrm{nm}$ region (data not shown) as the direct result of the two electron reduction of $\mathrm{Mo}(\mathrm{VI})$ to $\mathrm{Mo}(\mathrm{IV})$. This reaction proceeded rapidly leading to a bright green solution. After several minutes in acetonitrile and as shown in figure 1 (bottom), the band at $400 \mathrm{~nm}$ decreased exponentially with concomitant growth of a new peak at $360 \mathrm{~nm}$ with an isosbestic point at 370 $\mathrm{nm}$. The $\mathrm{d}$-d band at 600-800 $\mathrm{nm}$ also decreased slightly in intensity. These UV-vis spectral features are identical to those reported during the OAT chemistry of the related, $\left[\mathrm{TmMeMoO}{ }_{2} \mathrm{Cl}\right]$. The rapid growth of the $400 \mathrm{~nm}$ peak corresponds to the formation of the intermediate $\left[(\mathrm{L} 10 \mathrm{O}) \mathrm{MoOCl}\left(\mathrm{OPPh}_{3}\right)\right]$. The assignment of $400 \mathrm{~nm}$ peak observed in the $\mathrm{UV}$-vis as being due to the phosphine adduct was confirmed by ESI-MS recorded in positive mode in acetonitrile which revealed a cluster centered at $812.8 \mathrm{~m} / \mathrm{z}$, (figure 2) consistent with the simulated isotope pattern expected for the bridging intermediate (figure S1). Furthermore, monitoring the OAT reaction in benzene by ${ }^{31} \mathrm{P}$ NMR revealed three peaks, assignable to $\mathrm{PPh}_{3}(-$ $4 \mathrm{ppm}), \mathrm{OPPh}_{3}(26 \mathrm{ppm})$, and the $\left[(\mathrm{L} 10 \mathrm{O}) \mathrm{MoOCl}\left(\mathrm{OPPh}_{3}\right)\right]$ at $51 \mathrm{ppm}$. The subsequent exponential decay of the $400 \mathrm{~nm}$ band represents the dissociation of the $\mathrm{OPPh}_{3}$ product from the primary coordination sphere. This is consistent with the solvent assisted dissociative interchange $\left(\mathrm{I}_{\mathrm{d}}\right)$ mechanism proposed for a related system. ${ }^{25}$

The effect of pyridine on the reaction run in DMF or acetonitrile was probed through $\mathrm{UV}$-vis spectroscopy by allowing steady-state formation of the phosphine adduct to age for $\sim 10$ minutes followed by addition of an aliquot of pyridine. Introduction of pyridine resulted in the more rapid decay of the $400 \mathrm{~nm}$ shoulder with concomitant growth of bands at $500 \mathrm{~nm}$ and in the $600-800 \mathrm{~nm}$ region. The final spectrum is identical to the previously isolated and characterized trans-[(L10O) $\mathrm{MoOCl}(\mathrm{py})]$. Probing the same sample via ESI mass spectrometry also detected [(L10O) MoOCl(py)] at $613 \mathrm{~m} / \mathrm{z}$ (figure 3) confirmed by the simulated isotope pattern (data not shown). When the OAT was performed in pure pyridine, rapid formation of the $\left[(\mathrm{L} 10 \mathrm{O}) \mathrm{MoOCl}\left(\mathrm{OPPh}_{3}\right)\right]$ intermediate was again witnessed at $400 \mathrm{~nm}$ along with the rise of the broad Mo(IV) d-d transition band at 600-800 nm (figure 4). The stability of phosphine bound intermediate in pyridine is much less than that in DMF, acetonitrile, and benzene however as indicated by the near simultaneous appearance of a shoulder at $500 \mathrm{~nm}$ corresponding to formation of both the trans-[(L10O) $\mathrm{MoOCl}(\mathrm{py})]$ complex and the intermediate. Figure 5 shows the deconvoluted individual UV-vis spectra in the OAT reaction profile. Nevertheless the solvation of the phosphine oxide bound intermediate by pyridine is still quite slow relative to that seen with $\left[\mathrm{TmMeMoOCl}\left(\mathrm{OPPh}_{3}\right)\right]$ and $\left[\mathrm{Tp} * \mathrm{MoOCl}\left(\mathrm{OPPh}_{3}\right)\right]$ likely due to the steric protection of the intermediate afforded by the biphenyl rings of the (L10O) ligand. 
cis-[(L10O) $\left.\mathrm{MoO}_{2} \mathbf{C l}\right]$. The pure cis isomer of $\left[(\mathrm{L} 10 \mathrm{O}) \mathrm{MoO}_{2} \mathrm{Cl}\right]$ was synthesized according to published protocol by heating a crude isomeric mixture in DMF to assure the complete conversion of all the trans to the cis isomer. Under identical OAT conditions in acetonitrile and DMF, the cis isomer appears completely unreactive based on the unchanged UV-vis spectrum over many days. Moreover, analysis of the OAT reaction mixture by ESI-MS revealed no detectable phosphine adduct and only the starting dioxo complex was observed. However, when the OAT reaction of $c i s-\left[(\mathrm{L} 10 \mathrm{O}) \mathrm{MoO}_{2} \mathrm{Cl}\right]$ was performed in pyridine as a solvent, OAT occurred and could be followed by the appearance of the Mo(IV) d-d transition band at 600-800 nm and the intense absorption at $500 \mathrm{~nm}$ reminiscent of the optical spectrum of trans$[(\mathrm{L} 10 \mathrm{O}) \mathrm{MoOCl}(\mathrm{py})]$ (figure S2). Thus in contrast to trans $-\left[(\mathrm{L} 10 \mathrm{O}) \mathrm{MoO}_{2} \mathrm{Cl}\right]$ which underwent OAT reaction in all solvents (vide supra), the reaction with the cis isomer proceeded only in pyridine. In addition, and consistent with our previously reported OAT results, even in pyridine the cis isomer reacted at least 20 times slower than the trans isomer (figure S3). ${ }^{12}$ The redox potential contribution to the substantial variation in the two observed rates of OAT reactivity appears to be inadequate because the difference in the $\mathrm{Mo}(\mathrm{VI} / \mathrm{V})$ redox potential between the isomers is quite small $(<100 \mathrm{mv}),{ }^{15}$ which cannot account for the substantial variation in the two observed rates. More interestingly, the lack of OAT reactivity by the cis isomer in acetonitrile and DMF compared to pyridine suggests the crucial effect of solvent. The ${ }^{1} \mathrm{H}$ NMR of cis$\left[(\mathrm{L} 10 \mathrm{O}) \mathrm{MoO}_{2} \mathrm{Cl}\right]$ in $\mathrm{d}_{5}$-pyridine revealed only the cis isomer, eliminating the possibility that rapid isomerization of the cis to the trans isomer in pyridine could account for its reactivity in pyridine but not in $\mathrm{ACN}$ or DMF. ${ }^{29}$

In order to better understand the effect of geometry at the dioxo center with OAT rate we conducted computational studies (for details see Table S1). The two reaction steps i.e. binding to phosphine and displacement of the phosphine oxide by solvent, were computationally modeled for the $\left[(\mathrm{L} 10 \mathrm{O}) \mathrm{MoO}_{2} \mathrm{Cl}\right]$ complexes in order to determine the origin of the observed stereospecificity. Transition states for three pathways were identified for step 1 of the reaction (scheme 2): binding of the phosphine to either oxo group of the cis reactant (cis path); binding to the trans reactant at the oxo group $\mathrm{O} 2$, which is trans to the ligand oxygen atom $\mathrm{O} 1$ (trans $t$ path); and binding to the trans at the cis oxo group O3, which is roughly 90 degrees from $\mathrm{O} 1$ and O2 (trans $c$ path). The pseudo-first order rate constants in Table 1 were obtained by combining zero-point and thermal energy corrections to obtain predicted free energies of activation $G_{a}$. The computational results given in Table 1 correctly predict that the trans $c$ reaction pathway is the most likely, and that step 1 tends to be slower than step 2. However, the agreement is only qualitative, with rate constants much too low predicted for $\mathrm{k}_{2}$ ' and for the cis $\mathrm{k}_{1}$ '. Rate constants are difficult to predict quantitatively for complex systems, where a $1 \mathrm{kcal} / \mathrm{mol}$ error in $G_{a}$ corresponds to more than a factor of 5 in reaction rate. For step 1, the computed entropic contribution to $G_{a}$ alone is nearly $13 \mathrm{kcal} / \mathrm{mol}$. Solvent effects have also been neglected in the present calculations.

Natural bond order (NBO) analyses were carried out on the step 1 reactants and transition states in an attempt to explain the greater relative stability of the trans $c$ transition state. Selected results are summarized in Table 2. Before the reaction, the electron-deficient metal pulls electron density from the ligands in the complex. In the cis reactant, each of the three oxygens is 
aligned along a different axis in the octahedral complex, and this allows maximum donation into the empty $d$ orbitals of the metal, accounting for the relatively strong Mo-O1 bond $(R=1.971 \AA$ for cis, $2.018 \AA$ for trans) and the slight relative stability of the cis to the trans overall, with $\Delta G$ (cis-trans) $=2.3 \mathrm{kcal} / \mathrm{mol}$. When the phosphine attaches to either of the two oxo's, electron density donated by the phosphorus increases the electron density at the metal, which weakens the Mo-O1 bond. In all three transition states, the Mo-O1 bond distance has increased to $2.045 \AA$, but this is a greater weakening of the bond in the cis structure than in the trans, and therefore the cis has the highest barrier to reaction.

Of the two oxo's in the trans path, $\mathrm{O} 3$ is the better electron acceptor (charge $=-0.39 e$ for $\mathrm{O} 3,-0.45 e$ for $\mathrm{O} 2$ ) because it is able to donate more electron density than $\mathrm{O} 2$, which shares an axis with $\mathrm{O} 1$. This favors $\mathrm{O} 3$ for attachment of the phosphine, and is consistent with the smaller change in Mo-O3 bond distance upon formation of the transition state in the trans $c$ path than the trans $t(\Delta R=0.106 \AA$ for trans $c$ and $\Delta R=0.131 \AA$ for trans $t)$. During reaction, the HOMO of the $\mathrm{PMe}_{3}$ preferentially acts as a sigma donor to the lowest unoccupied orbital of one of the oxygens. As shown in Figure 6, the LUMOs in each of the three step 1 transition states span a metal $d$ orbital and an Mo-O $\pi^{*}$ orbital ending at the attachment site of the phosphine.

cis-[(L3S) $\left.\mathrm{MoO}_{2} \mathbf{C l}\right]$. The UV-Vis spectrum for the OAT reaction of $\left[(\mathrm{L} 3 \mathrm{~S}) \mathrm{MoO}_{2} \mathrm{Cl}\right]$ with phosphine in DMF and acetonitrile shows an absorbance increase at $500 \mathrm{~nm}$ and between $600-$ $900 \mathrm{~nm}$ producing a red solution after $\sim 10$ minutes (figure S4). The non-exponential kinetics and the lack of isosbestic points suggest a competing elementary reaction. The red solution was found to persist for weeks. We postulated that the red solution did not contain the phosphine adduct or [(L3S)MoOCl(solvent)] species, but rather it was the $\mu$-oxo dimer, as the addition of pyridine had no effect. Based on published results and our other observations reported here either the phosphine oxide intermediate or the solvent adduct would be expected to react with pyridine to yield the mononuclear species, i.e. [(L3S)MoOCl(py)]. Immediate analysis of the OAT reaction mixture in acetonitrile by mass spectrometry did led to the detection of the $\left[(\mathrm{L} 3 \mathrm{~S}) \mathrm{MoOCl}\left(\mathrm{OPPh}_{3}\right)\right]$ intermediate isotopic cluster at $704 \mathrm{amu}$ (figure $\mathrm{S} 5$ ) however also detected was the presence of $[(\mathrm{L} 3 \mathrm{~S}) \mathrm{MoOCl}]_{2} \mathrm{O}$ at 867 amu (figure S6). Analysis after one day showed that the phosphine intermediate had decomposed, but the $\mu$-oxo dimer cluster at $867 \mathrm{~m} / \mathrm{z}$ remained. A reasonable explanation for these observations is that the less bulky methyl groups on the thiolate ligand do not prevent $\mu$-oxo dimerization of the [(L3S)MoOCl(solvent)] species formed after OAT.

In contrast, mixing of the metal complex and phosphine in pyridine generated [(L3S $\left.) \mathrm{MoOCl}\left(\mathrm{OPPh}_{3}\right)\right]$ followed by the growth of the $500 \mathrm{~nm}$ band and $\mathrm{d}-\mathrm{d}$ transition band from $\mathrm{Mo}(\mathrm{IV})$ at $800 \mathrm{~nm}$ with a tight isosbestic point at $405 \mathrm{~nm}$ indicating only two absorbing species in solution (figure S7). Figure 7 shows the individual deconvoluted UV-vis spectra in the OAT reaction profile. The rate of formation of $\left[(\mathrm{L} 3 \mathrm{~S}) \mathrm{MoOCl}\left(\mathrm{OPPh}_{3}\right)\right]$ extracted at $500 \mathrm{~nm}$ is $\mathrm{k}_{\text {lobs }}=$ $6.96 \times 10^{-4} \mathrm{~s}^{-1}$ (Table 3). Upon reaching steady state, the phosphoryl adduct decomposed by releasing $\mathrm{OPPh}_{3}$ as monitored by the decreased absorption intensity at $500 \mathrm{~nm}$ to complete the oxygen atom transfer. The decomposition rate of intermediate to products is $\mathrm{k}_{2 \mathrm{obs}}=5.92 \times 10^{-5} \mathrm{~s}^{-}$ 1 
Catalytic Oxygen Atom Transfer. The catalytic OAT of trans-[( $\left.\mathrm{L} 10 \mathrm{O}) \mathrm{MoO}_{2} \mathrm{Cl}\right]$ and cis[(L3S) $\left.\mathrm{MoO}_{2} \mathrm{Cl}\right]$ were monitored in 50:50 v/v DMF and $\mathrm{d}_{6}$-DMSO with 10-fold excess of $\mathrm{PPh}_{3}$ by ${ }^{31} \mathrm{P}$ NMR. The cis isomer of $\left[(\mathrm{L} 10 \mathrm{O}) \mathrm{MoO}_{2} \mathrm{Cl}\right]$ was not examined due to its extremely slow OAT rate in any solvent other than pure pyridine and pyridine has been shown to inhibit the catalytic cycle. ${ }^{25}$ The reaction $\left(\mathrm{Me}_{2} \mathrm{~S}=\mathrm{O}+\mathrm{PPh}_{3} \rightarrow \mathrm{Me}_{2} \mathrm{~S}+\mathrm{OPPh}_{3}\right)$ was followed by the growth of phosphine oxide $(27 \mathrm{ppm})$ over time. The rate of catalytic OAT by trans-[(L10O) $\left.\mathrm{MoO}_{2} \mathrm{Cl}\right]$ is $\mathrm{k}_{\mathrm{cat}}=4.26 \times 10^{-5} \mathrm{~s}^{-1}$. Upon completion of the reaction, precipitation of a white solid ensued which was isolated by vacuum filtration and washed with copious amounts of hexane to remove excess solvents and $\mathrm{OPPh}_{3}$. IR characterization of the white solid confirmed its identity as $\left[(\mathrm{L} 10 \mathrm{O}) \mathrm{MoO}_{2} \mathrm{Cl}\right]$, thus provided direct evidence that the mononuclear complex is the active catalyst. cis-[(L3S) $\left.\mathrm{MoO}_{2} \mathrm{Cl}\right]$ also demonstrated catalytic conversation of phosphine $(-5 \mathrm{ppm})$ to phosphine oxide (27 ppm) as shown by ${ }^{31} \mathrm{P}$ NMR with $\mathrm{k}_{\text {cat }}=5.28 \times 10^{-5} \mathrm{~s}^{-1}$. A stoichiometric OAT reaction of cis-[(L3S) $\left.\mathrm{MoO}_{2} \mathrm{Cl}\right]$ with $\mathrm{PPh}_{3}$ monitored by ${ }^{31} \mathrm{P}$ NMR in DMF showed $100 \%$ conversion to $\mathrm{OPPh}_{3}$ followed by rapid coloration to dark purple red indicating $\mu$-oxo dimer formation. The experiment indicates that the mononuclear complex transferred an oxygen atom to the phosphine acceptor, but dimerization occurred soon after as the ligand lacks steric bulk to protect the Mo center from dimerization.

\section{Experimental}

Preparation of Compounds. All syntheses were performed under a dinitrogen or argon atmosphere using standard Schlenk or drybox techniques. Acetonitrile, ether, dichloromethane and THF were freshly purified using an Innovative Technology solvent purification system. All other solvents were dried with appropriate drying agents and distilled prior to use. Silica gel (SilicAR Silica Gel 150, 60-200 Mesh $60-200$ mesh) used in adsorption chromatography was obtained from Mallinckrodt while the filtering agent Celite was obtained from Aldrich. The heteroscorpionate ligands $(\mathrm{L} 10 \mathrm{OH}, \mathrm{L} 3 \mathrm{SH})$ utilized in this study was synthesized according to previous reports. The synthesis and detailed characterization of $\left[(\mathrm{L} 10 \mathrm{O}) \mathrm{MoO}_{2} \mathrm{Cl}\right]$ stereoisomers and $\left[(\mathrm{L} 3 \mathrm{~S}) \mathrm{MoO}_{2} \mathrm{Cl}\right]$, are reported elsewhere. ${ }^{13,15}$

Physical Methods. Electrospray mass spectra (ESI-MS) were recorded on a Finnigan LCQ iontrap mass spectrometer equipped with an ESI source (Finnigan MAT, San Jose, CA) in positive ion mode. A PC with Navigator software version 1.2 (Finnigan Corp., 1995-1997), was used for data acquisition and plotting. Isotope distribution patterns were simulated using the program Molecular Weight Calculator 6.42. GC-MS detection of dimethylsulfide was performed on the Varian Chrompack Saturn 2000R GC-MS containing auto sampler operated under the Varian MS Workstation System Control software version 6.6. UV-visible spectra were recorded using a Cary $50 \mathrm{UV}$-visibility spectrophotometer under PC control using the Cary WinUV software. Infrared spectra were collected $\mathrm{KBr}$ disks on a ThermoNicolet Nexus 670 FT-IR spectrometer under PC control and are reported in wavenumbers.

Oxygen Atom Transfer Kinetics. A $2.5 \mathrm{mM}$ solution of $\mathrm{LMoO}_{2} \mathrm{Cl}$ in acetonitrile, DMF, benzene, and pyridine was reacted with an excess of 50-fold $\mathrm{PPh}_{3}$ at $30(1)^{\circ} \mathrm{C}$ using a jacketed quartz cell attached to a circulating bath controlling the temperature. Fresh samples were prepared for each kinetic run and solutions were preequilibrated at $30^{\circ} \mathrm{C}$ in a water bath prior to 
any measurements. Tight isosbestic points were observed throughout the reaction indicating the presence of only two absorbing species. All reactions were monitored using a Cary $50 \mathrm{UV}$-Vis spectrometer under PC control. Rate constants for OAT were extracted at $700 \mathrm{~nm}$ or $500 \mathrm{~nm}$ and where appropriate global fitting of the data were performed with OLIS Spectral Works version 3.0.8 kinetic software.

Catalytic OAT Studies. In a typical experiment, $6.5 \mathrm{mg}\left(1.26 \times 10^{-5} \mathrm{~mol}\right)$ of the metal complex and a 10-fold excess of $\mathrm{PPh}_{3}\left(6.29 \times 10^{-3} \mathrm{~mol}\right)$ were dissolved in a 50:50 v/v mixture of DMF and $\mathrm{d}_{6}$-DMSO with a total volume of $1.0 \mathrm{~mL}$ in a NMR tube. The ${ }^{31} \mathrm{P}$ NMR kinetic experiment was performed on a $400 \mathrm{MHz}$ Varian FT-NMR spectrometer with the automated temperature controller set at $30^{\circ} \mathrm{C}$. Prior to kinetic measurements the NMR sample was equilibrated at $30^{\circ} \mathrm{C}$ and spectra were recorded every 15 minutes under PC control. The detection of dimethyl sulfide (DMS) by GC-MS confirmed the reduction of DMSO via oxo abstraction from Mo(IV) intermediate. In control experiments without metal complex under identical conditions, OAT conversion of $\mathrm{PPh}_{3}$ to $\mathrm{OPPh}_{3}$ was not observed.

Computational Methods. Full geometry optimizations, vibrational calculations, and natural bond order (NBO) analyses were carried out with Gaussian 03, ${ }^{30}$ using the B3LYP density

functional method, ${ }^{31,32}$ with Dunning's cc-pVDZ basis set ${ }^{33}$ for the main group atoms and the CEP-121G effective core potential and basis set of Stevens et al. ${ }^{34}$ for the metal center. In the computations, $\mathrm{PMe}_{3}$ was used in place of $\mathrm{PPh}_{3}$ for simplicity.

\section{Acknowledgements}

This work was supported in part by grants CHE-0313865 (CJC) and CHE-0202535 (ALC) from the NSF. The NSF-MRI program grants CHE-0320848 and CHE-0216563 are acknowledged for support of the X-ray diffraction and computational facilities, respectively, at San Diego State University. We thank Dr. LeRoy Lafferty for assistance with the ${ }^{31} \mathrm{P}$ NMR kinetic studies. 


\section{References}

1 R. A. Sheldon and J. K. Kochi, 'Metal-Catalyzed Oxidation of Organic Compounds', Academic, 1981.

2 R. H. Holm, Chem. Rev., 1987, 87, 1401.

3 L. K. Woo, Chem. Rev., 1993, 93, 1125.

4 J. H. Enemark, J. J. A. Cooney, J. J. Wang, and R. H. Holm, Chem. Rev., 2004, 104, 1175.

$5 \quad$ R. Hille, Chem. Rev., 1996, 96, 2757.

6 Z. Xiao, C. G. Young, J. H. Enemark, and A. G. Wedd, J. Am. Chem. Soc., 1992, 114, 9194.

7 W. E. Cleland, K. M. Barnhart, K. Yamanochi, D. Collison, F. E. Mabbs, R. B. Ortega, and J. H. Enemark, Inorg. Chem., 1987, 26, 1017.

8 S. A. Roberts, C. G. Young, C. A. Kipke, W. E. Cleland, K. Yamanouchi, M. D.

Carducci, J. H. Enemark, and Inorg. Chem., 1990, 29, 3650.

9 F. E. Inscore, R. McNaughton, B. L. Westcott, M. E. Helton, R. Jones, I. K. Dhawan, J. H. Enemark, and M. L. Kirk, Inorg. Chem., 1999, 38, 1401.

10 S. A. Roberts, C. G. Young, W. E. Cleland, R. B. Ortega, and J. H. Enemark, Inorg. Chem., 1988, 27, 3044.

11 Z. Xiao, M. A. Bruck, J. H. Enemark, C. G. Young, and A. G. Wedd, Inorg. Chem., 1996, 35, 7508 .

12 J. T. Hoffman, S. Einwaechter, B. S. Chohan, P. Basu, and C. J. Carrano, Inorg. Chem., 2004, 43, 7573.

13 B. S. Hammes, B. S. Chohan, J. T. Hoffman, S. Einwaechter, and C. J. Carrano, Inorg. Chem., 2004, 43, 7800.

14 S. R. Davie, N. D. Rubie, B. S. Hammes, C. J. Carrano, M. L. Kirk, and P. Basu, Inorg. Chem., 2001, 40, 2632.

15 J. T. Hoffman, B. L. Tran, and C. J. Carrano, Dalton Trans,, 2006, 3822.

16 C. J. Carrano, B. S. Chohan, B. S. Hammes, B. W. Kail, V. N. Nemykin, and P. Basu, Inorg. Chem., 2003, 42, 5999.

17 K. Peariso, B. S. Chohan, C. J. Carrano, and M. L. Kirk, Inorg. Chem., 2003, 42, 6194.

18 B. Kail, V. N. Nemykin, S. R. Davie, C. J. Carrano, B. Hammes, and P. Basu, Inorg. Chem., 2002, 41, 1281.

19 M. A. Pietsch and M. B. Hall, Inorg. Chem., 1996, 35, 1273. 
20 P. D. Smith, A. J. Millar, C. G. Young, A. Ghosh, and P. Basu, J. Am. Chem. Soc., 2000, $122,9298$.

21 V. N. Nemykin, J. Laskin, and P. Basu, J. Am. Chem. Soc., 2004, 126, 8604.

22 V. N. Nemykin and P. Basu, Inorg. Chem., 2005, 44, 7494.

23 A. J. Millar, C. J. Doonan, P. D. Smith, V. N. Nemykin, P. Basu, and C. G. Young, Chem. Eur. J., 2005, 11, 3255.

24 B. W. Kail, L. M. Perez, S. D. Zaric, A. J. Millar, C. G. Young, M. B. Hall, and P. Basu, Chem. Eur. J., 2006, 12, 7501.

25 B. L. Tran and C. J. Carrano, Inorg. Chem., 2007, 46, 5429.

26 B. L. Tran and C. J. Carrano, Inorg. Chim. Acta, 2006, 360, 1961.

27 H. Taube, H. Myers, and J. L. Rich, J. Am. Chem. Soc., 1953, 75, 4118.

28 H. Taube, Angew. Chem. Intl. Ed. Engl., 1984, 23, 329.

29 J. T. Hoffman, M.S. Thesis 'Heteroscorpionate Model Complexes of Relevance to the Active Sites of Various Molybdenum and Zinc Metalloenzymes', San Diego State University, San Diego, 2005.

30 M. J Frish et al., Gaussian 03, Revision B.02, Gaussian, Inc., Wallingford, CT, 2004.

31 A.D. Becke, J. Chem. Phys., 1993, 98, 5648-5652.

32 C. Lee, W. Yang, and R.G. Parr, Phys. Rev. B, 1988, 37, 785-789.

33 T.H. Dunning, Jr., J. Chem. Phys., 1989, 90, 1007-1023.

34 W.J. Stevens, M. Krauss, H. Basch, and P.G., Jasien, Can. J. Chem., 1992, 70, 612-630. 
Scheme 1. Ligands referred to in this study

Scheme 1: Ligands refered to in this study
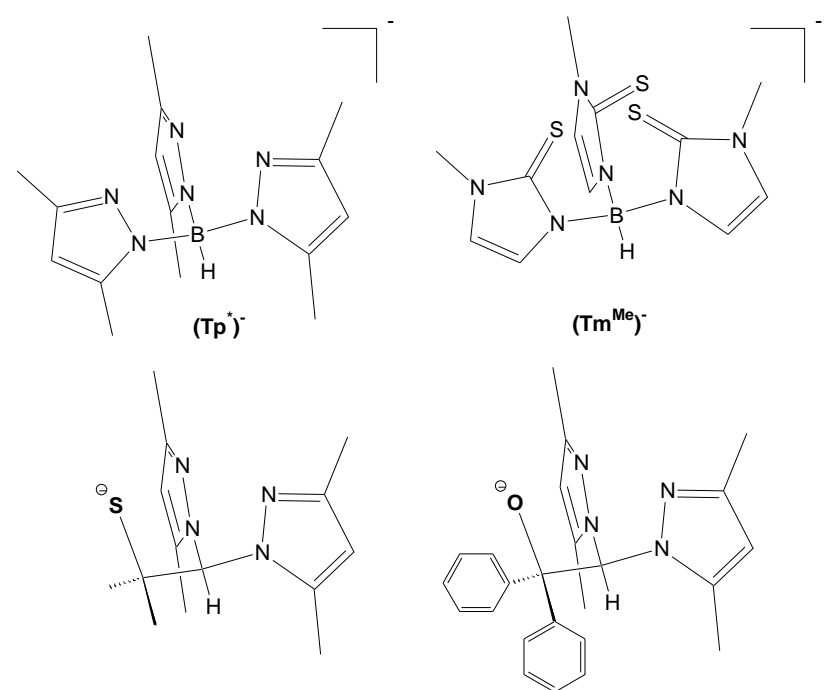

(L3S)-

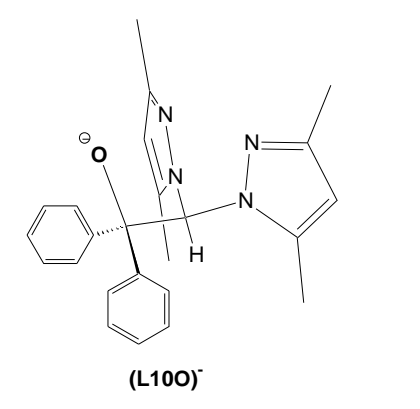


Scheme 2. Assignments of cis and trans OAT pathways.

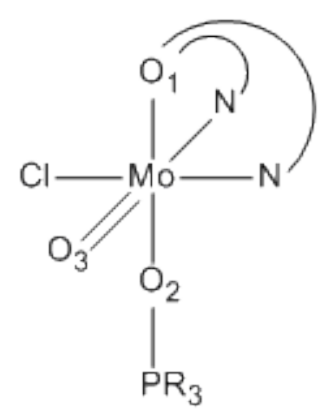

trans $t$ path

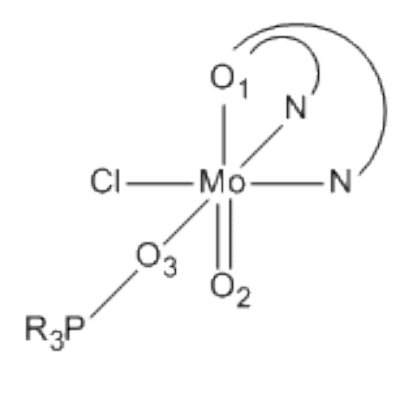

trans c path

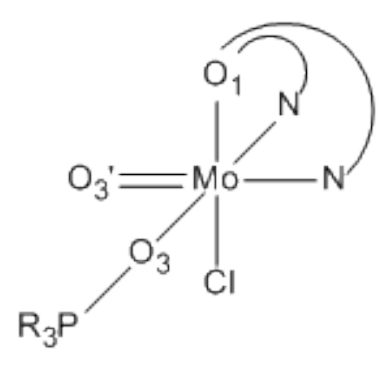

$$
\text { cis path }
$$

$\left(\mathrm{O}_{3}\right.$ and $\mathrm{O}_{3}{ }^{\prime}$ equivalent until attachment) 
Figure 1. Plot shows rapid formation of trans-[( $\left.\mathrm{L} 10 \mathrm{O}) \mathrm{MoOCl}\left(\mathrm{OPPh}_{3}\right)\right]$ indicated by the increase at $400 \mathrm{~nm}$ in acetonitrile (top). After several minutes, decomposition of the intermediate occurs pith : nnchontin nuintost $270 \mathrm{~mm}$
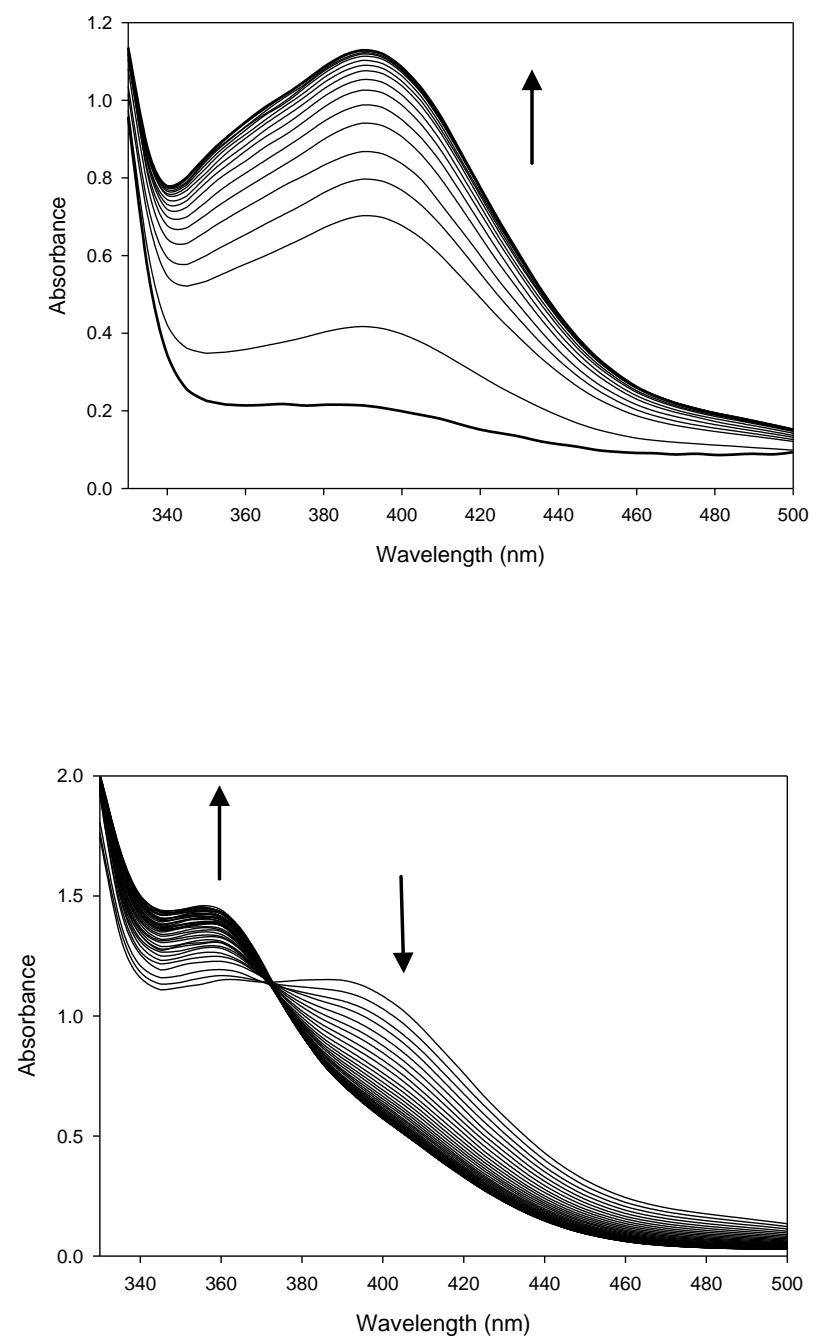
Figure 2. ESI-MS in positive mode of trans-[(L10O) $\left.\mathrm{MoOCl}\left(\mathrm{OPPh}_{3}\right)\right]^{+}$in acetonitrile.

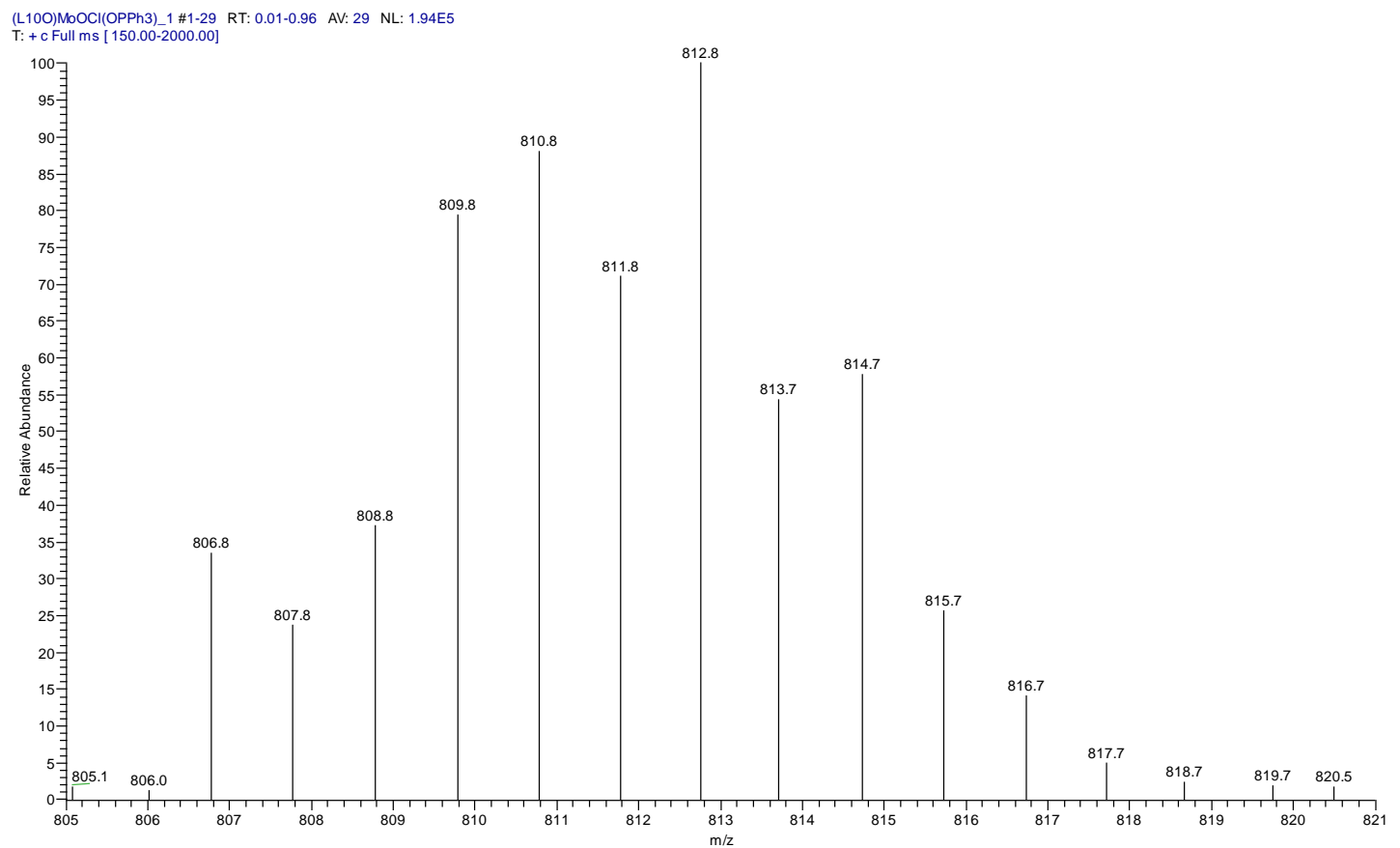


Figure 3. ESI-MS spectrum of [(L10O)MoOCl(pyridine $)]^{+}$.

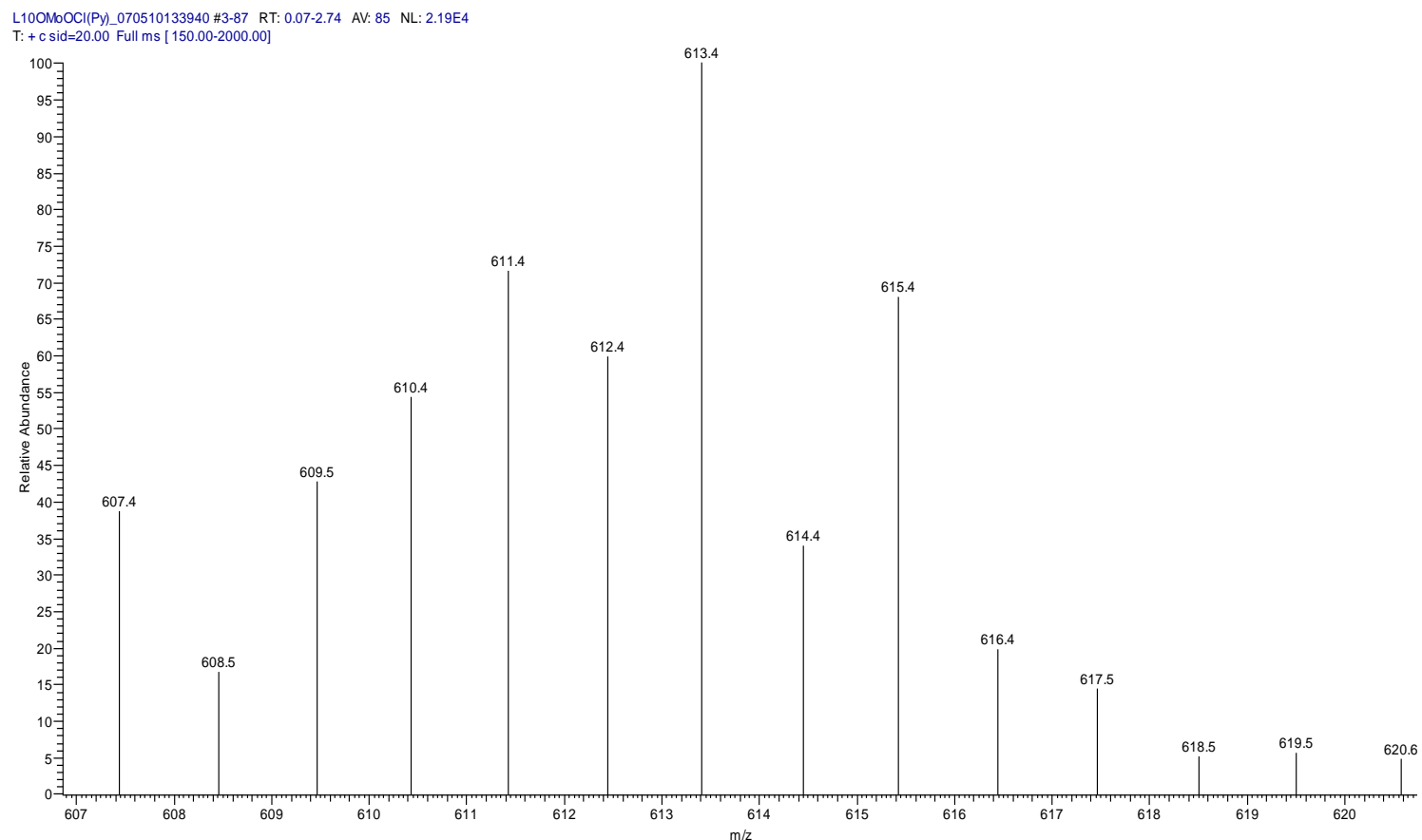


Figure 4. UV-Vis spectrum in pyridine shows rapid formation of trans-[(L10O)MoOCl( $\left.\left.\mathrm{OPPh}_{3}\right)\right]$ by the increase at $400 \mathrm{~nm}$. The $500 \mathrm{~nm}$ peak represents the simultaneous formation of [(L10O) MoOCl(pyridine)].

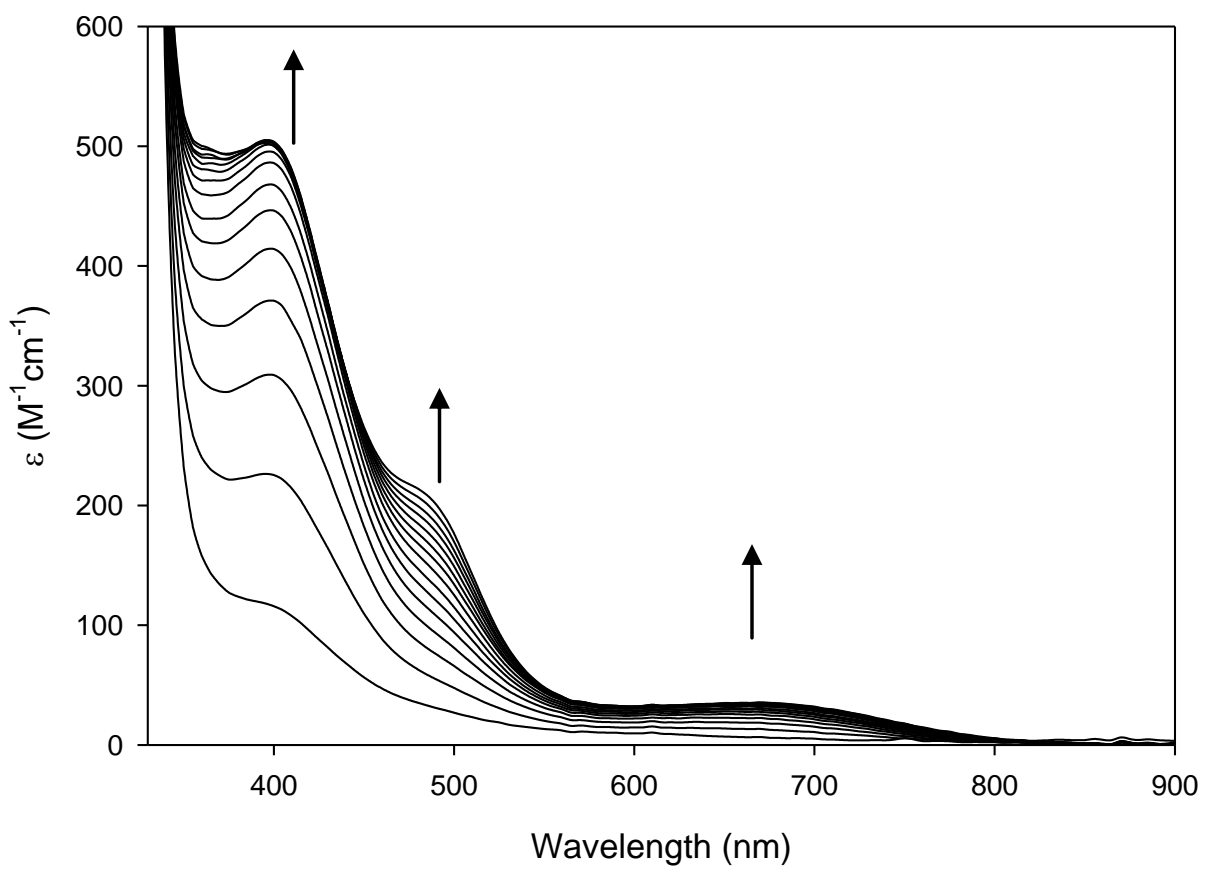


Figure 5. Spectral deconvolution of the OAT reaction between trans-[(L10O) $\left.\mathrm{MoO}_{2} \mathrm{Cl}\right]$ and $\mathrm{PPh}_{3}$ in pyridine. The biphasic OAT kinetic parameters extracted at $500 \mathrm{~nm}$ assumes an $\mathrm{A} \rightarrow \mathrm{B} \rightarrow \mathrm{C}$ kinetic scheme. The solid line represents the spectra of the starting trans-[( $\left.\mathrm{L10O}) \mathrm{MoO}_{2} \mathrm{Cl}\right]$, the dashed line the phosphine adduct, and the dotted line trans-[(L10O)MoOCl(py)].

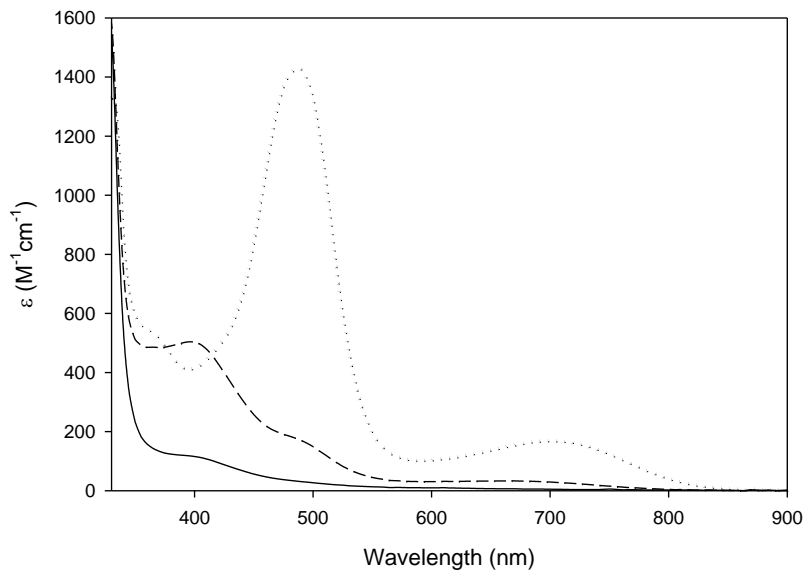


Figure 6. HOMO for trans $c$ transition state and LUMOs for all three step 1 transition states (after removing $\mathrm{PMe}_{3}$ ).

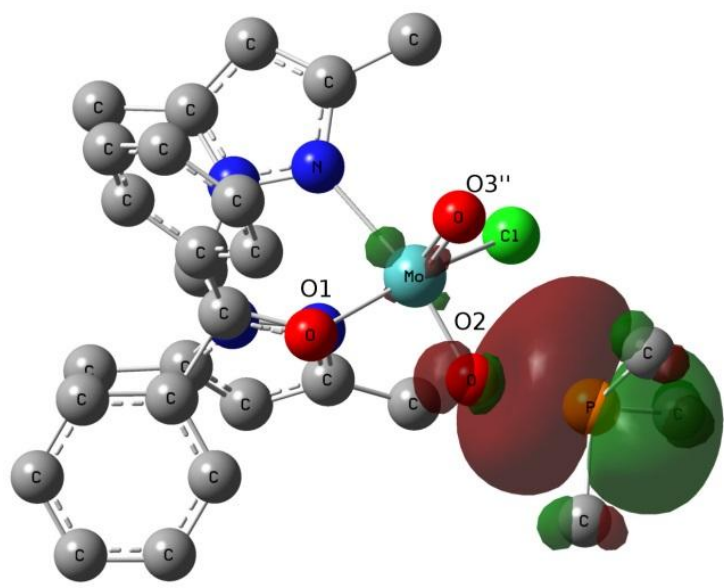

cis TS HOMO

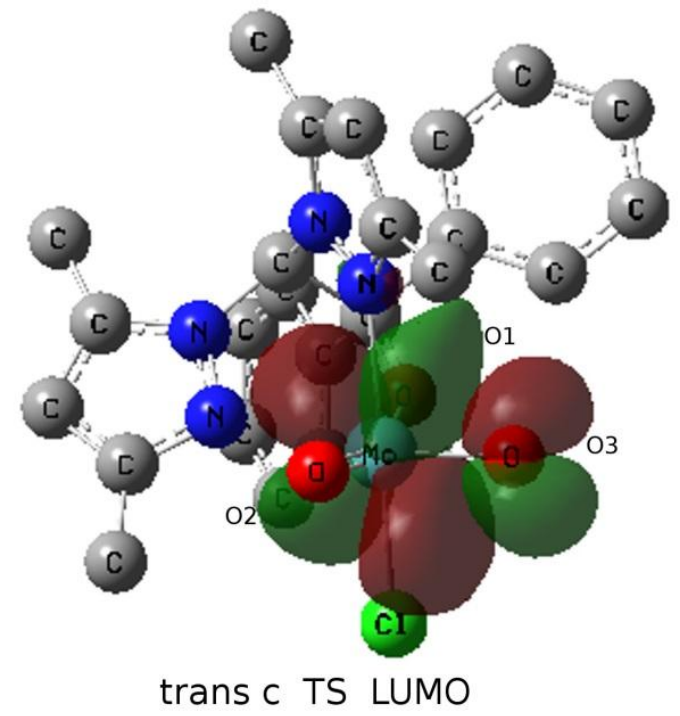

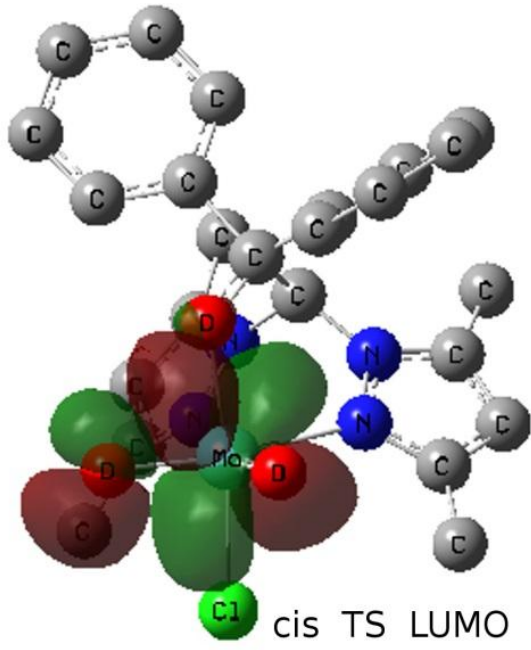

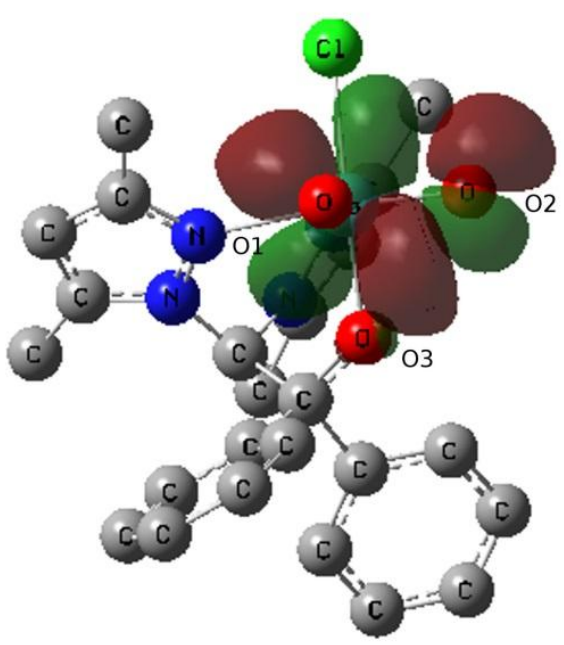

trans $\mathrm{t}$ TS LUMO 
Figure 7. OAT reaction of $\mathrm{PPh}_{3}$ with cis-[(L3S) $\left.\mathrm{MoO}_{2} \mathrm{Cl}\right]$ in pyridine. Right: the biphasic OAT kinetics extracted at $500 \mathrm{~nm}$ (right) where the points are the data and the solid line a fit to an A $\rightarrow$ B $\rightarrow$ C kinetic scheme. Left: Spectral deconvolution of the OAT reaction profile where the Solid line represents the spectra of the starting $c i s-\left[(\mathrm{L} 3 \mathrm{~S}) \mathrm{MoO}_{2} \mathrm{Cl}\right]$, the dashed line the phosphine adduct, and the dotted line [(L3S)) $\mathrm{MoOCl}(\mathrm{py})]$.
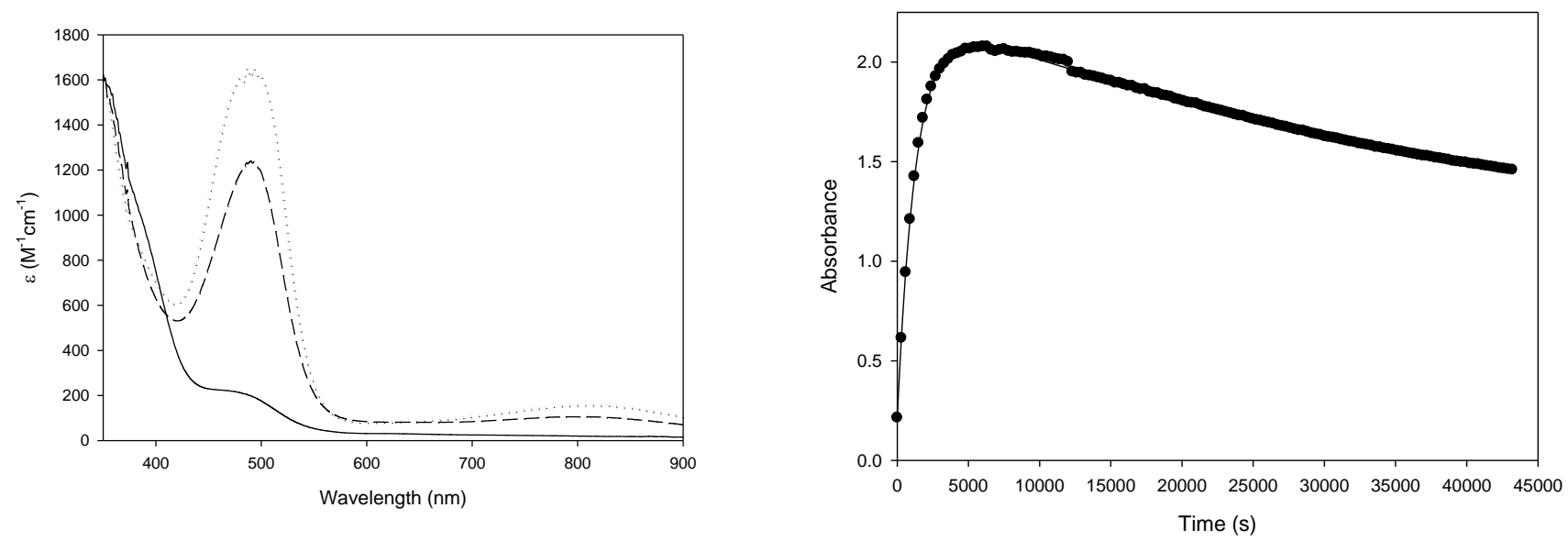
Table 1. B3LYP energies and free energies of activation and pseudo-first order rate constants.

\begin{tabular}{|l|l|l|l|}
\hline step 1 & $\boldsymbol{E}_{\boldsymbol{a}}(\mathbf{k c a l} / \mathbf{m o l})$ & $\boldsymbol{G}_{\boldsymbol{a}}(\mathbf{k c a l} / \mathbf{m o l})$ & $\boldsymbol{k}_{\mathbf{1}}{ }^{\prime}\left(\mathbf{s}^{-\mathbf{1}}\right)$ \\
\hline trans $c$ & 7.3 & 20.2 & $2 \cdot 10^{-4}$ \\
\hline trans $t$ & 11.9 & 24.3 & $2 \cdot 10^{-7}$ \\
\hline cis & 15.0 & 26.9 & $3 \cdot 10^{-9}$ \\
\hline step 2 & $\boldsymbol{E}_{\boldsymbol{a}}(\mathbf{k c a l} / \mathbf{m o l})$ & $\mathbf{G}_{\mathbf{a}}(\mathbf{k c a l} / \mathbf{m o l})$ & $\left.\boldsymbol{k}_{\mathbf{2}} \mathbf{s}^{-\mathbf{1}}\right)$ \\
\hline trans $c$ & 14.7 & 29.6 & $3 \cdot 10^{-9}$ \\
\hline
\end{tabular}


Table 2. Selected NBO charges and bond lengths.

\begin{tabular}{|l|r|r|r|r|r|}
\hline & \multicolumn{2}{|c|}{ Reactants } & \multicolumn{3}{c|}{ TS1 complexes } \\
\hline & \multicolumn{1}{|c|}{ Trans } & \multicolumn{1}{c|}{ Cis } & \multicolumn{1}{c|}{ Trans $\boldsymbol{c}$} & \multicolumn{1}{c|}{ Trans $\boldsymbol{t}$} & \multicolumn{1}{c|}{ Cis } \\
\hline O1 charge (e) & -0.68 & -0.66 & -0.71 & -0.72 & -0.71 \\
\hline O2,O3' charge (e) & -0.45 & -0.41 & -0.48 & -0.67 & -0.45 \\
\hline O3 charge (e) & -0.39 & -0.41 & -0.59 & -0.44 & -0.63 \\
\hline R(Mo-O1) $(\mathbf{\AA})$ & 2.019 & 1.971 & 2.045 & 2.045 & 2.046 \\
\hline R(Mo-O2,O3') $(\AA)$ & 1.733 & 1.721 & 1.728 & 1.864 & 1.710 \\
\hline R(Mo-O3) $(\AA)$ & 1.719 & 1.722 & 1.825 & 1.708 & 1.846 \\
\hline
\end{tabular}


Table 3. Kinetic Parameters for OAT.

\begin{tabular}{llll}
\hline Metal complex & Solvent & $\mathbf{k}_{\mathbf{1}}\left(\mathbf{s}^{\mathbf{- 1}}\right)$ & $\mathbf{k}_{\mathbf{2}}\left(\mathbf{s}^{\mathbf{- 1}}\right)$ \\
\hline trans $-(\mathrm{L} 10 \mathrm{O}) \mathrm{MoO}_{2} \mathrm{Cl}$ & ACN & $4.18 \times 10^{-2}$ & $3.80 \times 10^{-4}$ \\
& DMF & $6.08 \times 10^{-3}$ & \\
& DMF/pyridine & & $1.99 \times 10^{-4}$ \\
& pyridine & & $1.82 \times 10^{-4}$ \\
cis-(L10O) $\mathrm{MoO}_{2} \mathrm{Cl}$ & pyridine & $6.11 \times 10^{-6}$ \\
cis-(L3S) $\mathrm{MoO}_{2} \mathrm{Cl}$ & pyridine & & \\
& ACN and DMF & & \\
& & & $5.92 \times 10^{-5}$ \\
& & & \\
\hline
\end{tabular}

${ }^{a}$ The $\mathrm{k}_{1}$ and $\mathrm{k}_{2}$ could not be quantitatively measured due to competing $\mu$-oxo dimer reaction. 
Graphical Abstract - pictogram

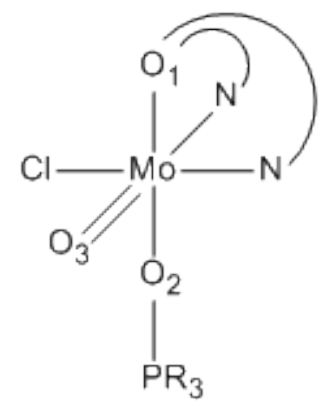

trans $t$ path

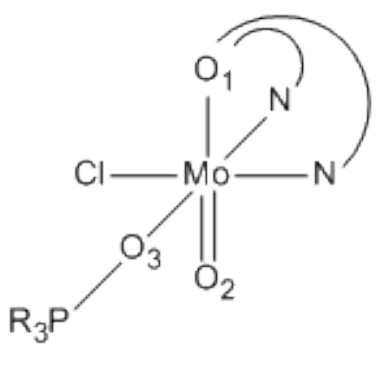

trans c path

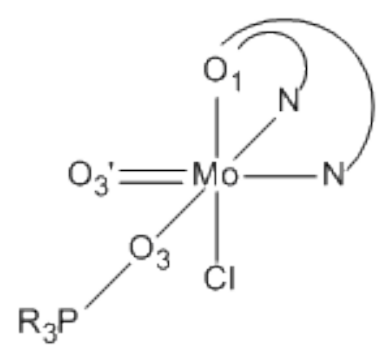

cis path

$\left(\mathrm{O}_{3}\right.$ and $\mathrm{O}_{3}{ }^{\prime}$ equivalent until attachment) 


\section{${ }^{*}$ Graphical abstract - synopsis}

The effects of stereochemistry (cis and trans) on OAT between heteroscorpionate dioxo Mo (VI) complexes and triphenylphosphine are examined. 